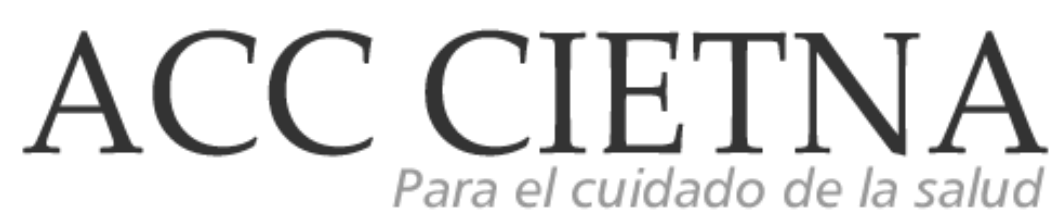

https://doi.org/10.35383/cietna.v6i2.255

\title{
Percepción de las madres sobre la vacuna contra el Virus del Papiloma Humano en una Institución Educativa Pública, 2016
}

\author{
Sanchez Mejia Eliana Estefany¹, Garay Lachira Alexandra Paola², Campos Bravo Yrma Lily ${ }^{3}$
}

\begin{tabular}{l} 
INFORMACIÓN DEL ARTÍCULO \\
\hline Historia del artículo: \\
Recibido el 23 de septiembre de 2019 \\
Aceptado el 18 de noviembre de 2019 \\
\hline Palabras clave: \\
Percepción \\
Vacuna VPH \\
Cáncer cuello uterino \\
\hline
\end{tabular}

\section{RESUMEN}

El cáncer de cuello uterino (CCU) a nivel mundial, es el cuarto cáncer más frecuente en las mujeres; por ello que el MINSA (2011), incorporó en el nuevo esquema de vacunas, la vacuna contra el Virus del Papiloma Humano. La presente investigación de enfoque cualitativo, abordaje metodológico estudio de caso; tuvo como objetivo: Describir y analizar la percepción de las madres sobre la vacuna contra el Virus del Papiloma Humano, y se sustentó en los conceptos de percepción de King y vacuna contra el virus del papiloma humano (VPH), según la Directiva Sanitaria para la Administración de la Vacuna N²55- 2015 del MINSA. Los sujetos, fueron 12 madres de las niñas del $5^{\circ}$ y $6^{\circ}$ de primaria de una Institución Educativa Pública, que cumplieron con los criterios de inclusión y que participaron libremente. La muestra se determinó por conveniencia y el tamaño por la técnica de saturación y redundancia; los datos se recolectaron mediante la entrevista semi estructurada; el análisis de datos fue mediante el análisis de contenido temático de Bardin; se tuvo en cuenta los criterios de rigor científico y rigor ético durante todas las etapas de la investigación. Se obtuvo como resultado 3 categorías: Percepción de las madres respecto a la vacuna contra el $\mathrm{VPH}$, acceso a la información y educación sobre la vacuna contra el VPH y reconociendo los efectos adversos de la vacuna. Resumiendo, se encontró que la percepción de las madres respecto a la vacuna está sujeto al nivel de información que ellas tienen y al factor, creencias; pues ello, determina la aceptación y continuidad o rechazo a la vacuna.

\footnotetext{
'Licenciada en enfermería en la Municipalidad del Distrito de San José, Chiclayo, Perú. Email: eliana_1805@hotmail.com 2Licenciada de enfermería en Establecimiento de Salud San Pablo, Huabal, Cajamarca, Perú. Email: ale.garay.lachira@hotmail.com ${ }^{3}$ Licenciada Especialista en Pediatría. Docente en Escuela de Enfermería, Universidad Católica Santo Toribio de Mogrovejo, Chiclayo, Perú. Email: ycampos@usat.edu.pe. ORCID: https://orcid.org/0000-0001-6432-7019
} 
Perception of mothers on the vaccine against Human Papiloma Virus in a Public Educational Institution, 2016

\section{ABSTRACT}

Keywords:

Perception

HPV vaccine

Cervical cancer
Cervical cancer (CCU) worldwide is the fourth most common cancer in women; Therefore, MINSA (2011), incorporated into the new vaccine scheme, the Human Papillomavirus vaccine. The present research of qualitative approach, methodological approach case study; It aimed to: Describe and analyze the perception of mothers about the vaccine against Human Papillomavirus, and it was based on the concepts of King's perception and vaccine against human papillomavirus (HPV), according to the Health Directive for the Administration of Vaccine $\mathrm{N}^{\circ}$ 255-2015 of the MINSA. The subjects were 12 mothers of the girls of the 5 th and 6 th grade of a Public Educational Institution, who met the inclusion criteria and who participated freely. The sample was determined for convenience and size by saturation and redundancy technique; the data was collected through the semi-structured interview; the data analysis was through the analysis of thematic content of Bardin; the criteria of scientific rigor and ethical rigor were taken into account during all stages of the investigation. Three categories were obtained as a result: Mothers' perception of the HPV vaccine, access to information and education about the HPV vaccine and recognizing the adverse effects of the vaccine. In summary, it was found that mothers' perception of the vaccine is subject to the level of information they have and to the factor, beliefs; therefore, it determines the acceptance and continuity or rejection of the vaccine.

\section{Introducción}

El cáncer de cuello uterino (CCU), a nivel mundial es el segundo cáncer más frecuente en las mujeres. Al respecto la Organización Mundial de la Salud (OMS) en el 2008 ha estimado que surgieron 500,000 casos nuevos por año, y para el 2012 hubo unos 530000 casos nuevos; siendo el factor principal de esta enfermedad el Virus del Papiloma Humano (VPH), que se transmite por vía sexual, por ello es importante la vacunación temprana en las niñas para prevenir esta grave enfermedad'.

Actualmente hay dos vacunas disponibles Gardasil

${ }^{\circledR}$ y Cervarix ${ }^{\circledR}$, estas vacunas ayudan a prevenir la infección por el VPH-16 y el VPH-18, causantes del $70 \%$ de todos los casos de pre cáncer y cáncer de cuello uterino, así como muchos casos de cáncer de ano, pene, vulva, vagina y garganta 2 .
El Ministerio de Salud (MINSA), desde el año 2011 , introdujo en el país la vacuna contra el VPH en el nuevo Esquema Nacional de Vacunación, con el objetivo de prevenir la infección con este virus responsable del CCU, verrugas genitales y otros tipos de cáncer frecuentes, esta vacuna se aplica a niñas de 10 años en todo el Perú, tanto de escuelas privadas como públicas ${ }^{1}$.

Sin embargo, en el sector de Salud de la región Lambayeque, la responsable de la Estrategia de Inmunizaciones de la Gerencia de Salud, manifestó que en el 2015, alrededor de 10 mil 400 niñas recibieron la primera dosis de dicha vacuna, pero para la segunda y tercera dosis muestran resistencia a la vacunación y a la fecha solo un $15 \%$ de las niñas cuenta con el esquema completo de tres dosis ${ }^{3}$. 
Esta situación ha generado en las investigadoras el planteamiento del problema ¿Cómo es la percepción de las madres sobre la vacuna contra el virus de Papiloma Humano en una Institución Educativa Pública, 2016?; teniendo como objeto de estudio de la investigación la Percepción de las madres sobre la vacuna y como objetivo general, describir y analizar la percepción de las madres sobre la vacuna contra el virus de Papiloma Humano.

La presente investigación, se justificó porque el cáncer Cervico-uterino, es un tipo de neoplasia de elevada prevalencia a nivel mundial y es el segundo tipo de cáncer más frecuente en la población femenina, responsable de más de 250000 muertes en el 2005, donde cerca del $80 \%$ ocurrieron en países en desarrollo 4 .

En la actualidad, la aceptación para la aplicación de esta vacuna no ha sido favorable, ya que se ha visto envuelta en mitos, que muchas veces han sido influenciados por el contexto sociocultural $y$ educativo de las madres de familia; esta misma situación también se vive a nivel mundial.

Se considera importante conocer las percepciones que tienen las madres sobre esta vacuna, para que los establecimientos de salud implementen estrategias en base a estas percepciones y mejorar el grado de aceptabilidad por parte de ellas a la hora de autorizar su aplicación, con el fin de alcanzar la cobertura nacional de vacunación, y proteger a las niñas contra esta terrible enfermedad y de esta manera contribuir a largo plazo en la disminución de la tasa de morbimortalidad por CCU.

Además, esta investigación servirá de referencia para realizar nuevas investigaciones, tanto cualitativas como cuantitativas, ya que no se cuenta con antecedentes a nivel local, lo que convierte al tema en inédito y a la vez relevante por tratarse de una estrategia nacional cuya responsabilidad recae exclusivamente en el profesional de enfermería.

\section{Metodología}

La investigación es de carácter cualitativo ${ }^{5}$ porque se desarrolló en una situación natural, rico en datos descriptivos, posee un plan abierto y flexible, orientando a la realidad en forma compleja y contextual. Que permitió a las investigadoras describir y analizar la percepción de las madres sobre la vacuna VPH dentro de su contexto natural.

El abordaje metodológico fue el estudio de Caso ${ }^{6}$, las investigadoras describieron y analizaron la información respecto a la percepción de las madres sobre la aplicación de la vacuna VPH, considerando en todo momento al sujeto como una entidad holística.

Para ello se utilizó los principios frecuentemente asociados al estudio de caso según Ludke y André tales como: dirigirse al descubrimiento, interpretar el contexto, citar la realidad en forma compleja y profunda los diferentes y conflictivos puntos de vista presentes en una situación social, utilizar un lenguaje y una forma más accesible en relación a otros relatos de investigación ${ }^{6}$.

Los sujetos de estudio fueron 12 madres, con hijas en edad escolar, quienes se caracterizaron por tener una edad que oscila entre los 30 y 45 años de edad, profesan la religión católica, en un $100 \%$ cuentan con nivel educativo primario, de estado civil casadas en un $90 \%$ y en un $80 \%$ dedicada al cuidado en el hogar.

Entre los criterios de inclusión tenemos: a las madres con hijas que cursan el $5^{\circ}$ y $6^{\circ}$ de primaria, que tengan la lera y/o 2 da dosis de la vacuna contra VPH y se encuentre registrado en su carnet y que hayan tomado la decisión voluntaria de no completar el esquema de vacunación.

Así mismo, se excluyeron a las madres con discapacidad auditiva $\mathrm{y} / \mathrm{o}$ de lenguaje, aquellas que participaron en la prueba piloto.

El tamaño de la muestra se obtuvo, a través de la técnica de saturación de datos, la cual ocurrió cuando los muestreos adicionales ya no proporcionaron nueva información, es decir cuando la información se tornó redundante o repetitiva. Así mismo, cada madre estuvo 
protegida por un código según orden de entrevista (VPH 001), teniendo en cuenta la naturaleza de la investigación con la finalidad de respetar la confidencialidad de los datos obtenidos en la entrevista; como los datos generales (estado civil, procedencia o nivel de instrucción).

La investigación tuvo como primer escenario los hogares de las madres de familia procedentes del Distrito de San José, ubicado a 11 km de Chiclayo, cuyo territorio se encuentra frente a las costas del mar; quienes cumplieron con los criterios de inclusión, previa autorización y coordinación de las mismas y como segundo escenario a la Institución Educativa $N^{\circ} 10222$ Elvira García y García, lugar donde se contactó a las alumnas quienes fueron portavoces del mensaje a sus madres para realizar la entrevista.

El instrumento de recolección de datos fue una guía de preguntas abiertas y como técnica se utilizó la entrevista semi estructurada ${ }^{5}$, que se llevaron a cabo con cada madre de familia y las investigadoras, a través del cual hubo un intercambio directo de información. La entrevista se centró siempre en el objeto de la investigación, es decir las percepciones de las madres y fue registrada en un grabador de voz, así mismo se utilizó un cuaderno de campo para anotar detalladamente las expresiones no verbales observadas en las madres.

En el procedimiento, este trabajo fue revisado por el comité metodológico de la Escuela de Enfermería-USAT, luego aprobado por el Comité de Ética de la Facultad de Medicina de la Universidad Católica Santo Toribio de Mogrovejo. Posteriormente se solicitó el permiso al médico jefe del Centro de Salud de San José, luego se estableció contacto con la enfermera encargada de la estrategia de inmunización para que facilite los registros de las niñas vacunadas contra el Virus del Papiloma Humano (registro A), así como también de aquellas que no completaron el esquema de vacunación (registro B), después de haber accedido a esas listas se procedió a realizar la prueba piloto a tres madres tomadas del registro B que permitió precisar mejor las preguntas.
Luego se determinó el número de alumnas que no cuentan con la tercera dosis de vacuna y se procedió a elegir la muestra por conveniencia, con las alumnas se envió un mensaje a la madre para que autorice la visita en su domicilio. Se procedió a la visita casa por casa con la finalidad de solicitar su participación informándoles sobre la investigación a realizar, asimismo se les dio a conocer que su participación es voluntaria y confidencial, solicitándoles el permiso correspondiente para la entrevista a través del consentimiento informado.

Se realiza las entrevistas a las madres en sus hogares y cada una duró aproximadamente entre 20 a 25 minutos, en todo momento se guardó la confidencialidad y comodidad, la investigadora siempre estuvo atenta al comportamiento de la madre para detener la entrevista o suspenderla si el caso lo ameritaba; el recojo de los datos duró un mes.

Una vez que se finalizó la recolección de datos se procedió, con la transcripción de las mismas y posteriormente fueron presentados a cada uno de los participantes para corroborar que lo expresado es lo correcto y para agregar algún dato más en algunos de los relatos proporcionados. Cabe mencionar que se tuvo que regresar al escenario hasta completar la muestra, teniendo en cuenta los criterios de saturación.

Al finalizar la recolección de datos se realizó las coordinaciones pertinentes con la Institución Educativa Elvira Garcia y García №10222, para brindar una sesión educativa a las madres del 5 to y 6to de primaria sobre la Vacuna VPH, enfermedades que previene, datos estadísticos y se aclaró las dudas de cada madre, esta sesión educativa estuvo dirigida por las investigadoras en compañía de la enfermera del Programa de inmunizaciones.

El análisis e interpretación de los datos se efectuó mediante el análisis de contenido, a través de las tres etapas: Pre análisis, codificación y categorización. Durante todo el desarrollo de la investigación se aplicaron los principios de la ética propuesto por Elio Sgrecia8: El principio de valor fundamental de la vida humana y el respeto a su 
dignidad, libertad y responsabilidad, beneficencia y de confidencialidad. También se tuvo en cuenta los criterios de rigor científico ${ }^{9}$ como la credibilidad, la transferibilidad o aplicabilidad y confirmabilidad.

\section{Resultados, análisis y discusión}

Después de entrevistar a las madres que cumplieron con los criterios de inclusión, se obtuvieron resultados a través del análisis de datos, los cuales fueron obtenidos en los hogares de las madres de familia del distrito de San José, escenario adecuado para que las madres expresen libremente las percepciones respeto al objeto de estudio.

PRIMERA CATEGORIA: percepción de las madres respecto a la vacuna contra el VPH

La percepción es el proceso de organizar, interpretar y transformar la información de los datos sensoriales y la memoria. Es un proceso de transacciones humanas con el medio ambiente. Les da sentido a las experiencias del individuo, representa su imagen de la realidad, e influye en su conducta. Una percepción se relaciona con experiencias pasadas, con el concepto de uno mismo (del yo), con la herencia biológica, con los antecedentes educativos y con los grupos socioeconómicos ${ }^{10}$.

En la presente investigación, la percepción estuvo establecida por el conjunto de sensaciones captadas por las madres a través de los sentidos y muchas veces se ha relacionado con experiencias pasadas respecto a la vacuna contra el VPH, emitiendo así una opinión sobre ella, dando como resultado la aceptación o rechazo de la vacuna a lo que llamamos reticencia.

Cabe acotar que la Organización Mundial de la Salud, define a la reticencia de la vacunación como la tardanza en aceptar la vacunación o el rechazo a las vacunas, pese a la disponibilidad de los servicios de la vacunación. La reticencia a la vacunación es compleja, tiene características específicas en cada contexto y varía según el momento, el lugar y la vacuna, incluye como el exceso de confianza, la comodidad y la seguridad. ${ }^{11}$

Por lo que se presenta las siguientes subcategorías donde se evidencia por un lado la aceptación de la vacuna y por el otro el rechazo a ella.

\subsection{ACEPTABILIDAD DE LA VACUNA VPH POR PERCEPCIÓN DE VULNERABILIDAD}

La vulnerabilidad, es entendida como un proceso multidimensional que confluye en el riesgo o probabilidad del individuo, hogar o comunidad, de ser herido, lesionado o dañado ante cambios o permanencia de situaciones externas y/o internas. ${ }^{12}$

Es por esto que la percepción de vulnerabilidad se refiere a la percepción subjetiva del riesgo de enfermar. En el caso de ya estar enfermo, correspondería a la aceptación del diagnóstico y su percepción de mayor vulnerabilidad hacia nuevas enfermedades o condiciones limitantes derivadas de la enfermedad 13 .

En la investigación, las madres de familia tienen aceptabilidad debido a la percepción de vulnerabilidad sobre la vacuna contra el VPH tal como se expresa en las siguientes unidades de análisis:

\section{“(..) Lo que recuerdo es que es una vacuna que cuidará y protegerá a las niñas contra el cáncer de cuello uterino...esa vacuna es nueva." VPHOOT. \\ “(..) Esta vacuna la envían para que se administre a las niñas de nivel primario, con el objetivo de proteger a las niñas del cáncer de cuello uterino, el cual es el responsable de la muerte de muchas mujeres (...)" VPHOO4.}

Como se puede evidenciar, un $60 \%$ de madres entrevistadas, aceptan la vacuna y reconocen que beneficiará a sus hijas, debido a que estas madres tienen una percepción de vulnerabilidad, entendida como el temor a que sus hijas se enfermen de cáncer de cuello uterino en el futuro; debido a que protegen a sus hijas a través de la administración de la vacuna contra el VPH y 
aceptan la vacuna, manifestando que es una buena opción para cuidarlas y protegerlas del cáncer de cuello uterino en el futuro, el cual es una de las principales causas de mortalidad en las mujeres.

Estos resultados coinciden con los de Wiesner ${ }^{14}$, que sus conclusiones fueron que la aceptabilidad a la vacuna varía en relación con el contexto sociocultural y educativo y promover la vacuna para prevenir una infección de transmisión sexual en niñas muy jóvenes ( $<12$ años) puede generar obstáculos para su aceptabilidad.

Es necesario recalcar que, en el estudio de caso, no todas las madres tuvieron una aceptabilidad frente a la vacuna, por lo contrario, hubo situaciones de rechazo como se evidencia en la siguiente sub categoría

\subsection{RECHAZO DE LA VACUNA CONTRA EL VPH POR PERCEPCIÓN DE AMENAZA CONTRA LA SALUD SEXUAL.}

El rechazo es el proceso y la consecuencia de rechazar (resistir, negar o refutar). Al manifestar o concretar el rechazo hacia algo, la persona deja en evidencia que no lo acepta o tolera.

Mientras que una amenaza, es entendida como un peligro o factor de riesgo externo de un sujeto o sistema, representado por un peligro latente asociado con un fenómeno físico de origen natural, de origen tecnológico o provocado por el hombre, que puede manifestarse en un sitio especifico, durante un tiempo de exposición determinado, produciendo efectos adversos en las personas, los bienes $\mathrm{y} / \mathrm{o}$ el medio ambiente. Matemáticamente expresado como la probabilidad de exceder un nivel de ocurrencia de un evento con una cierta intensidad, en cierto sitio y en cierto periodo de tiempo. ${ }^{15}$

En conclusión, el rechazo a la vacuna es la acción de negar la administración de ésta, debido a las creencias y la falta de educación que tienen las madres sobre ella, generando una percepción de amenaza contra la sexualidad, entendida como la probabilidad de que exista un peligro latente que aún no se desencadena, y que afecte al desarrollo de los órganos reproductivos femeninos de sus hijas, el cual causa miedo o pánico entre las madres y esto se corrobora con la investigación de Sánchez $\mathrm{L}^{16}$, donde se muestra que el $94 \%$ de las mujeres encuestadas tenía conocimiento de la vacuna, los factores de riesgo identificados en este estudio para no permitir la vacunación fueron: desconocer la existencia de la vacuna, carecer de información amplia de las enfermedades de transmisión sexual y el temor a que inicien vida sexual activa a edad más temprana. En conclusión, se identificaron como factores de riesgo de no permitir la vacunación a sus hijas, el no saber de la existencia de la vacuna, no tener información amplia de la misma y el temor a que inicien vida sexual activa a edad más temprana.

Tal como se evidencia en las siguientes unidades de análisis las madres de familia entrevistadas tienen una percepción de amenaza a la salud sexual de sus hijas ya que existen percepciones erróneas sobre la vacuna:

\section{“(..) Algunas mamás decían que no permitirían que vacunaran a sus hijas debido que la vacuna es un método anticonceptivo (...) Dicen que esa vacuna hace que las niñas inicien sus relaciones sexuales a temprana edad, también decían que las niñas no podrán ser mamás en el futuro." VPHOOT.}

“(..) Mi hija no recibió la segunda dosis de su vacuna porque ella estaba con su periodo menstrual, entonces tuvimos miedo a que se le pueda cortar su periodo, es por eso que no permití que continuara vacunándose, ella también tenía miedo de que se altere su sangre porque estaba con su menstruación (...)" VPH 001.

Según lo expresado por las madres de familia en sus discursos, un $40 \%$ no aceptan la vacuna ya que piensan que puede ocasionar un daño un físico, puede inducir a las relaciones sexuales a temprana edad o por las creencias que tienen. Esto se puede evidenciar como una percepción de amenaza traducida en el temor y miedo, por el cual impiden continuar con la vacunación, que se ve influenciado al nivel educativo primario de estas madres que impiden un mayor entendimiento o 
búsqueda de información sobre la vacuna y a las creencias que guardan generando un rechazo a la vacunación.

Por consiguiente, el hecho de que las madres se sientan amenazadas por esta percepción errónea se convierte en una barrera para la aceptabilidad de la vacuna, el cual tendrá por resultado el rechazo e impedimento de la administración de ella.

En este sentido, las investigadoras afirman que es fundamental que se eduque a las madres de familia sobre la vacuna contra el VPH, para eliminar las percepciones erróneas y dar paso a la aceptación para la administración de esta vacuna, contribuyendo así a la prevención de CCU y esto se va a lograr cuando las madres reciban la información y educación pertinente sobre la vacuna, esto da lugar a la siguiente categoría.

\section{CATEGORIA II: Acceso a la información y educación sobre la vacuna contra el VPH:}

La información está constituida por un grupo de datos ya supervisados y ordenados, que sirven para construir un mensaje basado en un cierto fenómeno o ente. La información permite resolver problemas y tomar decisiones, ya que su aprovechamiento racional es la base del conocimiento ${ }^{17}$.

Por otro lado, el término educación, se define como el proceso de socialización de los individuos. Al educarse, una persona asimila y aprende conocimientos. La educación también implica una concienciación cultural y conductual, donde las nuevas generaciones adquieren los modos de ser de generaciones anteriores ${ }^{17}$.

En conclusión, la información en salud se refiere a como la persona capta la información brindada; mientras que la educación en salud comprende la serie de metodologías para trasmitir una información con el fin de educar a la población adecuándose al nivel de educación de las personas.

De esta manera los profesionales sanitarios son un modelo importante para sus pacientes ${ }^{11}$, con la función de mantener la seguridad y confianza de lo que van a realizar para trasmitir en sus pacientes el objetivo propuesto, y que ellos logren comprender lo expuesto.

En las siguientes unidades de análisis, se puede observar que el $100 \%$ de madres manifiestan que ellas no recibieron educación alguna por parte del personal de salud, y que fueron sus hijas quienes les informaron lo poco que comprendieron cuando la enfermera les explico sobre la administración de esta vacuna, pero aun así las madres firmaron el consentimiento informado para la administración de dicha vacuna.

\section{“(..) Mi hija me entregó un documento que le había dado una enfermera, para firmar y autorizar la administración de la vacuna $\mathrm{VPH}$, pero no me explicaron personalmente para que era la vacuna, solo les dieron a conocer algo a nuestras hijas"... "mi esposo no quería que la vacunen porque no sabemos si es $100 \%$ segura, pese a ello con una pequeña duda me dijo: si la vacuna es para protégela averigua y que la vacunen"... pese a ello acepté la administración de la vacuna porque quería protegerla (...)" VPHOO6.}

\section{“(..) En una ocasión mi hija regresó del colegio y me dijo: mamá una enfermera estuvo en el aula y nos entregó este documento para que firmes porque quieren vacunarnos contra el cáncer al útero, para que no nos enfermemos, como yo trabajo todo el día le dije que en la noche hablábamos porque tenía que irme, luego lo pensé y tuve que firmar (...)" VPHOOT.}

En estas unidades de análisis se evidencia que las madres no tienen la información adecuada, y son sus hijas quienes les comunican lo poco que comprendieron cuando la enfermera les menciono respecto a la vacuna; la Directiva Sanitaria para la administración de la vacuna contra el Virus del Papiloma Humano(VPH)- Resolución Ministerial 255-2015 MINSA ${ }^{18,}$ respalda esta actividad educativa mencionado que la enfermera debe realizar sesiones educativas a los padres de familia e informar de manera clara y precisa los diferentes 
procedimientos que se realizaran bajo su autorización.

De este $100 \%$ de madres que no fueron comunicadas directamente por el personal de salud encargado y capacitado para la administración de la vacuna contra el VPH, solo un $30 \%$ se informaron acerca de esta vacuna VPH mediante el noticiero, y autorizaron la administración de esta vacuna.

\section{“(..) Autoricé que mi hija reciba esta} vacuna, porque según la información trasmitida en el noticiero, esta vacuna protegerá a las niñas y evitara que les de cáncer de cuello uterino en un futuro (...)" VPHOO2.

... "Yo autoricé que mi hija reciba la vacuna $V P H$, porque escuché en las noticias sobre lo importante que es esta vacuna, además que las protegerá del cáncer de cuello uterino (...)" VPHOO5.

Los medios de comunicación juegan un papel importante en la sociedad, porque son las herramientas mediante el cual los individuos son capaces de trasmitir o conocer una información. En este caso podemos analizar y recalcar que las madres conocen de la importancia de la vacuna contra el VPH y autorizan su administración, porque fue por medio del noticiero que se informaron.

A pesar de que existe un déficit de la educación correcta en salud por parte de la enfermera hacia las madres, podemos obtener que ellas sin dificultad alguna autorizan la administración de la vacuna contra el VPH, confiando en las directivas propuestas por el MINSA y aceptando la vacunación a pesar de las dudas o falsas percepciones que ellas tienen.

Asimismo, se reconoce que las niñas no logran comprender la información que la enfermera les trasmite y cuando van a comunicarle a sus madres, muchas veces esta información se distorsiona o simplemente comunican lo poco que recuerdan. Por consiguiente, la enfermera debe cumplir el rol como educador, teniendo como concepto que es el enfermero quien ayuda al paciente a aprender sobre su salud y sobre los procedimientos sanitarios que necesita realizar para recuperar o mantener su salud y en este caso ara obtener la autorización de la madre para la aplicación de la vacuna y de esta manera disminuir la resistencia a la vacunación por falsas percepciones.

\section{CATEGORIA III: reconociendo los efectos adversos de la vacuna contra el VPH}

La Resolución Ministerial No 255-2015 MINSA, menciona los efectos adversos esperados posterior a la vacuna contra el VPH, clasificándolos de la siguiente manera: efectos leves frecuentes, los cuales son reacciones locales como: induración, dolor local, reducción en el uso de brazo en la que se administra la vacuna, todo estos eventos ocurre dentro de las primeras 72 horas y puede tener una duración de 5 días; otras reacciones leves frecuentes pueden ser las reacciones sistémicas como: fiebre, decaimiento, fatiga, problemas para dormir, náuseas, vómitos, diarrea, dolor abdominal, mialgias, artralgias, rash generalizado y urticaria, estos síntomas presente dentro de las 24 horas y con una duración de 2 a 4 días ${ }^{18}$.

Por lo general, entre las reacciones graves poco frecuente se encuentra el síncope (algunas veces acompañado de movimientos tónico clónicos) entre los primeros 15 a 30 minutos. También se puede presentar entre 1 a 1.7 casos por cada millón de dosis las reacciones como anafilaxia entre los 15 a 30 minutos $^{18 .}$.

Asimismo, Leanes, el representante de la Organización Panamericana de la Salud/Organización Mundial de la Salud (OPS/OMS) en el Perú, respaldó la campaña de vacunación que emprende el Ministerio de Salud (MINSA) contra el VPH; fue claro al indicar que no se ha demostrado científicamente que la vacuna haya ocasionado las reacciones en ninguno de los casos que se han publicado. Así mismo mencionó, que para que una vacuna ingrese a un país primero hay una evaluación de la OMS que hace un análisis riguroso sobre la seguridad y eficacia de la vacuna, y en el Perú se cuenta con un comité asesor de 
inmunizaciones conformado por expertos de distintas instituciones ${ }^{19}$

Cabe mencionar que la Gerencia Regional de Salud, reporta que no se ha presentado ningún caso de ESAVI entorno a la administración de la vacuna contra el VPH. En las siguientes unidades de análisis se manifiestan la respuesta de las madres conforme a las reacciones post vacunación que presentaron sus hijas:

El $20 \%$ de niñas que se vacunaron, presentaron reacciones locales, como fue el dolor, este se define como "una experiencia sensitiva y emocional desagradable, asociada a una lesión tisular real o potencial". La percepción del dolor consta de un sistema neuronal sensitivo (nocioceptores) y unas vías nerviosas aferentes que responden a estímulos nocioceptivos tisulares; la nociocepción puede estar influida por otros factores (psicológicos) 20.

Así, otro grupo que representó el $10 \%$ de niñas que se vacunaron presentaron reacciones sistémicas como fiebre y malestar general, tal como se evidencia en la siguiente unidad de análisis:

\section{“(..) Mi hija tuvo un poco de fiebre $y$} malestar general, me asusté al principio, pero después le consulté a su tía y me dijo que le administre una pastilla paracetamol (...)" VPHOO2.

Por último, el $70 \%$ de niñas que se vacunaron no presentaron reacción adversa alguna.

\section{“(..) Mi hija no presentó ninguna reacción a la vacuna." VPHOO4.}

\section{“(..) Hablé con mi hija y ella no me refirió molestia alguna (...)" VPHOO5.}

En relación a las unidades de análisis el $70 \%$ de niñas vacunadas no presentaron reacción algún, este resultado se corrobora con lo expresado por el director de la OPS y la OMS en el Perú, quien manifestó que esta vacuna no produce los efectos que se le están atribuyendo, lo único que produce es dolor y fiebre muy leve o moderada, en algunos casos $^{19}$.

Después de analizar cada unidad sobre los efectos post vacunación, se concluye que la vacuna contra el VPH es medida de prevención para el cáncer de cuello uterino, en un $70 \%$ esta vacuna no presenta reacciones adversas y cabe mencionar que el la Gerencia Regional de Salud no se ha reportado ningún caso de ESAVI entorno a la administración de la vacuna contra el VPH.

\section{Conclusiones}

La percepción de las madres respecto a la vacuna contra el VPH está sujeto al nivel de información que ellas poseen $y$ al factor, creencias, determinando su aceptación y continuidad o el rechazo de la vacuna contra el VPH.

Las percepciones emitidas por las madres están relacionadas con experiencias pasadas, siendo percibidas de dos maneras: como percepción de vulnerabilidad y amenaza, que hace que las madres tomen decisiones de protección para sus hijas y por consiguiente acepten la vacuna, ya que perciben el riesgo de enfermar de Cáncer de Cuello Uterino, y como percepción de amenaza, que genera una percepción errónea, debido al miedo ocasionado por la falta de información de esta vacuna, la cual impide la prevención del Cáncer de Cuello Uterino en las niñas escolares.

La información que poseen las madres respecto a la vacuna VPH es incompleta, pues el $100 \%$ de ellas refieren que no fueron educadas mediante sesiones educativas por las enfermeras y que solo obtuvieron información por parte de sus hijas y por los medios de difusión, generando temor y miedo a la vacunación y por consiguiente el rechazo o resistencia a completar el calendario de vacunación.

Los efectos adversos post vacunación, guardan relación con lo mencionado en la norma técnica, evidenciándose un 30\% presentaron reacciones adversas distribuidas de la siguiente manera: 10\% reacciones sistémicas, $20 \%$ reacciones locales y un $70 \%$ no presentaron ninguna reacción.

\section{Bibliografía}

1. Organización Mundial de la Salud. Papilomavirus Humanos (VPH) y cáncer Cervicouterino. Noviembre del 2014, Perú. 
[Acceso 02 de septiembre del 2015]. Disponible en: http:/ /www.who.int/mediacentre/factsheets / fs $380 /$ es/

2. American Cancer Society.Vacunas contra el Virus del Papiloma Humano, 19 de Julio del 2014. [Ultimo acceso 02 de septiembre del 2015]. Disponible en: https://old.cancer.org/acs/groups/cid/docu ments/webcontent/002781-pdf.pdf.

3. RPP Noticia. Lambayeque: menores se resisten a aplicación de vacuna contra el virus del papiloma humano. Perú, 26 de Agosto del 2015. [Ultimo Acceso 30 de agosto del 2015]. Disponible en: http://www.rpp.com.pe/2015-08-26lambayeque-menores-se-resisten-aaplicacion-de-vacuna-contra-el-vphnoticia_830353.html

4. Barreto J. "Cobertura alcanzada con la vacuna del Papiloma Humano en relación con el grado de aceptabilidad por parte de los padres de familia de tres instituciones educativas vinculadas al centro de salud $\mathrm{n}^{\circ} 1$ de la ciudad de Ambato, periodo septiembre 2013 a julio 2014" [Tesis en internet, acceso 28 de Noviembre del 2016]. Disponible en: http://repo.uta.edu.ec/bitstream/123456789 /9504 / 1 /JEANNETTE\%20BARRENO\%20L\%C3\% 93PEZ.pdf

5. Hernández R, Fernández $C$ \& Baptista $M$. Metodología de la investigación.5ed. Mexico. McGRAW-HILL, 2010.

6. Ludke M, Marli E. Pesquisa em Educação: Abordagens Qualitativas. E.P.U. Editora Pedagógica e Universitaria LTDA. André-São Paulo; 1986.

7. Lenise do Prado $M$, Souza $M, \&$ otros. Investigación cualitativa en enfermería. Metodología didáctica. Washington. Serie PALTEX Salud y Sociedad 2000, 2013.

8. Sgrecia E. Manual de Bioética - Modelo personalista. 1999.

9. Gerrish K, Lacey A. Investigación en enfermería. 5ed. España. McGRAW-HILL, 2006.
10. Marriner A. Raile Alligood M, Modelos y teorías en Enfermería. 6ta ed. Barcelona: Elsevier; 2007.

11. Organización Mundial de la Salud. Resumen de las conclusiones y recomendaciones del Grupo de Expertos de la OMS de Asesoramiento Estratégico en materia de inmunización sobre reticencia a la vacunación. [Revista en internet, acceso 25 de Noviembre del 2016]. Disponible en:

http://www.who.int/immunization/program mes_systems/Summary_of_SAGE_VaccineHesi tancy_2pager_FINAL_Feb2015_espagnol.pdf? ua

12. Buzzo G. Vulnerabilidad social: Nociones e implicancias de políticas para Latinoamérica a inicios del siglo XXI. [Revista en internet, acceso 28 de Noviembre del 2016]. Disponible en:

http://www.cepal.org/publicaciones/xml/3/ 8283 /Gbusso.pdf

13. SIDA-AIS. Modelos Psicologicos de la Salud que han abordado el VIH/SIDA.Modelo creencias de Salud. Disponible en: http://www.sida-aids.org/psicologiasida/29-modelos-de-salud/15-

14. Wiesner C, Piñeros M, Trujillo L, Cortés C, Ardila J. Aceptabilidad de la vacuna contra el Virus Papiloma Humano en padres de adolescentes, en Colombia [revista en internet, acceso23 de Agosto del 2015]. Disponible en: http://www.scielosp.org/pdf/rsap/v12n6/v1 2n6a08

15. Cardona A, Omar D. Evaluacion de la Amenaza, la Vulnerabilidad y el riesgo: elementos para el ordenamiento y la planeación del desarrollo. En los desastres no son naturales. [Revista en internet, acceso 28 de Noviembre del 2016]. Disponible en: http://www.eird.org/deslizamientos/pdf/spa /doc10186/doc10186-2.pdf. [último acceso 26 de Noviembre del 2016]. 
16. Sánchez L, Lechuga A, Milla R, Lares E. Conocimiento y aceptación de la vacuna contra el virus del papiloma humano entre madres de estudiantes de la ciudad de Durango, México. [Revista en internet, acceso 22 de Agosto del 2015]. Disponible en: http://www.medigraphic.com/pdfs/ginobsm ex/gom-2013/gom 132c.pdf

17. Garcia L. División Académica de Educación y Artes; 13 de agosto del 2012. [Acceso a internet, 26 de Noviembre del 2016]. Disponible en: http://galeon.com/lenygarcia/investigacion.p df

18. Ministerio de Salud. Directiva Sanitaria Para la Administración de la Vacuna contra el Virus del Papiloma Humano (VPH). Lima; 2015.

19. Organización Panamericana de la Salud /Organización Mundial de Salud. 18 de Marzo del 2015. Disponible en: http://www.paho.org/per/index.php?option= com_content\&view =article\&id=2894:opsrespalda-campana-de-vacunacion-contrael-vph\&Itemid=900 [Último acceso 28 de Noviembre del 2016].

20. Puebla F. Tipos de dolor y escala terapéutica de la O.M.S. Dolor iatrogénico, Disponible en: http://www.sld.cu/galerias/pdf/sitios/aneste siologia/tipos_de_dolor.pdf. [Último acceso 28 de Noviembre del 2016]. 